\title{
NOVAS TECNOLOGIAS E GLOBALIZAÇÃO: CAMINHOS PARA A CONSTRUÇÃO DO CONHECIMENTO EM LÍNGUA ESPANHOLA
}

\author{
SILVA, Cleber Cezar PrP-UFG ${ }^{1}$
}

RESUMO: O estudo que propomos executar foi uma pesquisa-ação, desenvolvida em nossa realidade escolar. Buscamos nos subsidiar em um arcabouço teórico para fazer as discussões nos temas que abordamos em nosso estudo como: o processo da globalização, o uso das novas tecnologias na educação, o uso do blog, a aprendizagem colaborativa. E ao final pudemos fazer uma discussão na nossa analise dos dados, já que nossa pesquisa foi executada em uma turma de $1^{\circ}$ ano do Ensino Médio, com o propósito de executar a aprendizagem colaborativa juntamente com o uso de novas tecnologias, no ensino de língua espanhola.

Palavras Chaves: Globalização. Novas tecnologias. Aprendizagem colaborativa. Pesquisaação. Blog.

\section{NEW TECHNOLOGIES AND GLOBALIZATION: WAYS TO BUILD KNOWLEDGE IN SPANISH}

ABSTRACT: We proposed to perform an action research study, which was developed in our school environment. We looked for support in a theorical basement to make discussions about the topics we discussed in our study such as: the process of globalization, the use of new technologies in education, use of blog, collaborative learning. After that we did a discussion in our data analysis. Since our survey was conducted in a class of first year of high school, in order to perform collaborative learning, along with the use of new technologies in teaching the Spanish language.

Keywords: Globalization. New technologies. Collaborative learning. Research action. Blog.

\section{1 - Introdução}

As discussões a nós apresentadas neste século XXI envolvem uma gama de informações a respeito da tecnologia e da informação, em especial por vivermos em uma sociedade literalmente tecnológica, por isso não seria diferente no campo educacional. A par dessas transformações oriundas com a globalização, para atender as necessidades do homem um modelo de educação vem corroborar com inúmeros fatores a EAD (Educação a Distância)

\footnotetext{
${ }^{1}$ Mestrando em Estudos Linguísticos pela Universidade Federal de Goiás - Goiânia. Professor de Língua Espanhola nas IES de educação básica: Colégio Sagrado Coração de Jesus e Colégio Estadual Professor Ivan Ferreira - Pires do Rio - GO, professor substituto, área de Língua Portuguesa no Instituto Federal Goiano, Campus Urutaí-GO. E-mail. clebercezar@hotmail.com.
} 
como uma ferramenta eficaz e segura para a formação educacional e profissional, a qual conta com todos os deveres e direitos de um curso totalmente presencial.

Muito se tem observado em relação aos novos paradigmas da educação. As Novas Tecnologias de Informação e Comunicação (NTCIs) ${ }^{2}$ fazem parte das nossas práticas cotidianas, refletindo-se no processo educacional. Masetto (2000) em seus estudos nos mostra a presença e a influência que a tecnologia tem na sociedade contemporânea e na educação. Esse momento de transição porque passa a educação se deve a vários fatores relacionados à vida humana, desde os sociais, econômicos, culturais e, nessa perspectiva, deve se observar que o ensino necessita se adequar à realidade de nossos alunos.

Com essas transformações em curso a educação volta-se para o aluno, tornando-o centro do processo ensino-aprendizagem, em que o professor transforma-se num facilitador. Essas mudanças no ambiente educacional fazem com que o comportamento dos alunos e professores seja diferenciado daquela da sala de aula presencial. Ou seja, o ciberespaço ${ }^{3}$ (espaço virtual) possibilita acontecer uma aprendizagem tanto individual (interaprendizagem) quanto colaborativa (auto-aprendizagem) num processo de autonomia da aprendizagem.

O ciberespaço por meio do uso das Novas Tecnologias torna o aluno um aprendiz ativo, bem sucedido, pois ele em uma sala de aula presencial pode não ter coragem de expor suas idéias por medo de represália. Na sala de aula virtual (ciberespaço) o mesmo é avaliado de acordo com suas participações e acesso ao espaço, sua representação on-line é através de textos relacionados ao conteúdo devidamente planejados pelo professor, um mediador da aprendizagem. Nesse contexto a interação de um aluno com o outro é muito importante, pois assim acontece uma aprendizagem colaborativa e significativa a cada indivíduo.

E para que aconteça a aprendizagem no ciberespaço, deve o professor-facilitador em seu planejamento estabelecer metas, objetivos e resultados esperados, pois as abordagens e as competências têm de ser elaboradas de acordo com a realidade do público a qual se destina o curso. O aluno tem que ter acesso a essa Nova Tecnologia, pois sua participação é

\footnotetext{
${ }^{2}$ Novas Tecnologias de Informação e Comunicação (NTICs) são as tecnologias e métodos para comunicar surgidas no contexto da Revolução Informacional, "Revolução Telemática" ou Terceira Revolução Industrial, desenvolvidas gradativamente desde a segunda metade da década de 1970 e, principalmente, nos anos 1990. A imensa maioria delas se caracteriza por agilizar, horizontalizar e tornar menos palpável (fisicamente manipulável) o conteúdo da comunicação, por meio da digitalização e da comunicação_em redes (mediada ou não por computadores) para a captação, transmissão e distribuição das informações (texto, imagem estática, vídeo e som). Aqui especificamente faremos uso do termo para designar o uso do computador e Internet.

${ }^{3}$ Ciberespaço é um espaço de comunicação que descarta a necessidade do homem físico para constituir a comunicação como fonte de relacionamento, dando ênfase ao ato da imaginação, necessária para a criação de uma imagem anônima, que terá comunhão com os demais.
} 
fundamental para que aconteça uma interação entre participante-facilitador e participanteparticipante que leve a cabo uma aprendizagem colaborativa. É nesse ciberespaço que o ensinar e o aprender sai da sala de aula presencial e se constitui numa aprendizagem autônoma e emancipadora ao aprendiz.

O uso das ferramentas tecnológicas (mediação pedagógica) vem nos auxiliar no processo ensino-aprendizagem, proporcionando a nossos alunos se envolverem na construção de seu próprio aprendizado e na de sua autonomia. Com todos esses avanços nós professores vivemos numa década em que somos envoltos por um “aprendizado técnico docente”, segundo Kenski (2006), e isso é necessário, pois não podemos ficar presos no tradicionalismo enquanto nossos alunos são pertencentes a comunidades distintas, como é o caso das virtuais.

A par das discussões acerca das Novas Tecnologias e a educação, buscaremos em nossa pesquisa através do uso do blog uma ferramenta tecnológica conduzir o nosso educando a conhecer um pouco mais da história e cultura de alguns países hispanohablantes numa abordagem de aprendizagem colaborativa.

\section{2 - O processo globalizacional e as novas tecnologias - caminhos à educação}

A globalização tem feito com que o ser humano aja de forma precisa e rápida, e isso acontece também com os processos nos quais esteja envolvido. E assim com as recorrentes literaturas buscamos entender que

a globalização pode ser vista como um conjunto de estratégias para realizar a hegemonia de conglomerados industriais, corporações financeiras, majors do cinema, da televisão, da música e da informática, para apropriar-se dos recursos naturais e culturais, do trabalho, do ócio e do dinheiro dos países pobres, subordinando-os à exploração concentrada com que esses atores reordenaram o mundo na segunda metade do século XX. (CANCLINI, 2003, p. 29).

E com isso, o processo de saturação informacional que estamos vivenciando se deve às Novas Tecnologias, e à comunicação eletrônica, a qual traz consigo diversas formas de comunicação (e-mails, chats, fóruns, grupos de discussões, blogs e outros). Por isso nos vemos obrigados a criar processos pessoais de filtragem das informações sob pena de sermos soterrados pelo volume de heterogeneidade a que nos cerca. 
A tecnologia é uma ferramenta de aprendizagem, em que de forma on-line tem feito surgir salas de aula virtuais, onde para que possa acontecer uma aprendizagem ativa é necessário acontecer uma interação dos membros do grupo. O indivíduo interage melhor após conhecer o outro como isso não se dá face-a-face, é indispensável que haja um espaço para as apresentações de cada um. Tomemos por referência um blog pessoal (diário virtual), onde é registrada a vida pessoal e as atividades diárias do participante. Quando conhecemos o outro, a interação se dá de forma mais significativa, como foi constatado nos estudos de Pallof; Pratt (2002, p.60) “o contato virtual oferece muitas vantagens para os tímidos, que podem, pelo uso do computador, interagir com as pessoas sem ter de enfrentar as dificuldades do contato físico ou visual”.

A linguagem provoca à inserção do aluno no desenvolvimento, constando-se que a escola presencial é polifônica e isso a diferencia da escola virtual. As Novas Tecnologias a nós apresentadas pelas escolas virtuais, através da tela do computador, vem sendo uma nova possibilidade aos alunos, pois os mesmos ficam longe dos espaços constituídos de violência e das dificuldades de acesso à escola. Esse ambiente virtual se constitui através da interação e consequentemente da aprendizagem colaborativa, cujos alunos não se sentirão sozinhos, pois tudo será mediado por um instrutor (professor facilitador). Por isso aluno e facilitador irão juntos desenvolver suas atividades, como nos afirma Kenski (2003, p.55) “o ambiente virtual de aprendizagem se constrói com base no estímulo à realização de atividades colaborativas, em que o aluno não se sinta só, isolado, dialogando apenas com a máquina ou com o instrutor também virtual”.

Sabemos que a linguagem é uma "ferramenta" que temos a nosso favor e na era digital se constitui, fortalece e evolui com a cultura. A linguagem científica ou comunicacional é instituída nesse meio, pois o saber científico irá gerar um outro saber, aqui designado por Kenski (2003) como “instrumental”, isso forma e organiza um estoque de conhecimentos. O desencadeamento das novas formas de linguagem faz com que a linguagem audiovisual, que temos como um meio de aprendizagem e que envolve sons, imagens, cores, proporcione ao indivíduo as experiências globais unificadas, assim nós professores-facilitadores conduzimos o nosso aluno a se constituir um mediador de seu conhecimento.

$\mathrm{Na}$ constituição de significados e construção de conhecimentos encontramos a linguagem midiatizada, a qual leva o aluno a partir de leituras de textos a saírem do contexto em que foram produzidos para buscar seu próprio significado, o aluno será o próprio construtor do sentido. Esse texto eletrônico carregado de uma nova linguagem, mediação 
entre o oral e o escrito, o imagético e o digital, o hipertexto, desencadeia nas palavras de Kerckhove (1997) apud Kenski (2003, p.61) “a inteligência humana libertou-se do peso da lembrança para se aplicar na inovação”.

E com essas observaçõs fazemos menção a Ortiz (2008 p.67) que: “embora falemos em expansão das línguas, claro, é metafórica. As línguas não adquirem falantes. São os locutores que adquirem e usam as línguas”, tal afirmação vem corroborar para esse surgimento das linguagens e gêneros que vêm deslocando no meio tecnológico, claro que são decorrentes da criação e expansão humana, oriundas da globalização.

Marcuschi (2005) em seu estudo traz uma discussão acerca dos gêneros textuais e coloca a linguagem como um meio de entendê-los, o que leva-nos a fazer uma triangulação com as definições por ele estabelecida em seu estudo, ressaltando partes essências. Para ele, o impacto dos gêneros textuais virtuais está diretamente interligado na linguagem e na vida social do ser humano contemporâneo. As várias formas de expressão reunidas, texto, som e imagens interferem na natureza dos recursos linguísticos utilizados pelo sujeito.

Essas Novas Tecnologias traz novos rumos na vida do ser humano, bem como essa cultura eletrônica provoca uma nova economia na escrita, pois acontecem algumas reduções e abrevaituras nas palavras utilizadas no meio virtual se assemelhando com a oralidade e assim isso surge o letramento digital. Sabemos que o discurso eletrônico como um gênero textual no domínio da mídia virtual é recente e ainda carece de novos estudos para melhor se atrelar ao mundo contemporâneo. Além disso, com essa evolução cabe observar a posição das escolas frente ao uso desse discurso eletrônico, uma vez que os livros didáticos já têm se apresentado com esse discurso, mas a escola não se faz apenas do livro didático, pois existe uma cultura e crenças pré-estabelecidas a serem observadas. Pois nessa relação David Crystal (2001:2) apud Marcuschi (2005) afirma que a cada Nova Tecnologia o mundo todo se renova, é uma ilusão que logo desaparece; e será que isso também pode acontecer no meio educacional?

Os domínios de produção e processamento textual em que surgem os gêneros, cujo ambiente permite “culturas variadas”, o uso da linguagem se dá com certa informalidade, menor monitoramento e cobrança pela fluidez do meio pela rapidez do tempo. Marcuschi (2005) no decorrer de seu estudo faz algumas pausas e reflexões em torno de alguns gêneros virtuais, que cabe apenas mencioná-los: os e-mails (mensagens eletrônicas); os chats (batepapos) em salas abertas; chat reservado; o bate-papo ICQ (agendado); os chats em salas privadas; entrevista com convidado; e-mails educacionais (aulas virtuais por e-mail); aulas 
chat (O chat educacional); vídeo-conferência interativa; listas de discussões e os blogs (Weblogs).

A partir de todos esses gêneros mencionados podemos salientar que o espaço virtual não supre o espaço educacional presencial, ele amplia, cria novas dimensões para o acesso à educação, novas possibilidades de comunicação e agregação, novas oportunidades para o avanço na ação e na formação do cidadão que habita os múltiplos espaços das escolas - e das suas múltiplas linguagens. Cabe ainda destacarmos que a relação entre a escrita nas Novas Tecnologias está desconstruindo toda a oposição existente entre fala e escrita A escrita virtual é plena de expressão da fala, isso possibilita um novo letramento, pois a linguística está diante de um fenômeno que a obriga a rever alguns de seus postulados teóricos.

As Novas Tecnologias aplicadas no meio educacional para os devidos fins educativos nos mostram que o conhecimento é trabalhado com fins e objetivos distintos. Mas isto deve ser observado, pois existem vários fatores que podem não corroborar para um bom desempenho da aplicabilidade das mesmas em prol de um ensino de qualidade e que busque realmente o aprendizado do aluno. Assim, centramos o foco no professor e sabemos que alguns ainda não pertencem a uma alfabetização tecnológica.

De acordo com Rodrigues (1992) apud Leite; Sampaio (2002, p. 58), “o processo de alfabetização altera o perfil social do homem, transformando-o em um ser político e participativo”. Nessa formação do homem é que visamos à alfabetização tecnológica do professor, pois ele tem que atuar como um ser político dotado de conceitos e metodologias em sua vida cotidiana seja na escola ou na sociedade, como um ser participativo colaborando para um processo de aprendizagem de seus alunos voltado para a realidade, partindo até mesmo da necessidade ou da própria realidade dele.

Sabemos que as políticas público-governamentais em seus vários programas destinados à educação mencionam uma grande preocupação com uma educação de qualidade, mas inúmeros fatores vêm ao desencontro dessa realidade: escolas sucatadas, os baixos salários dos professores, laboratórios sem manutenção e técnicos responsáveis. Nessa situação como podemos desenvolver um processo de ensino-aprendizagem corroborando com uma educação de qualidade? Ficamos a mercê, caminhamos da forma que podemos e aquele profissional que queira se especializar ou até mesmo buscar novos recursos para suas aulas, acaba agindo por si próprio.

A partir das discussões ocorridas, observamos uma síntese do que venha ser a alfabetização tecnológica: 
(...) a alfabetização tecnológica do professor como um conceito envolve o domínio contínuo e crescente das tecnologias que estão na escola e na sociedade, mediante o relacionamento crítico com elas. Este domínio se traduz em uma percepção global do papel das tecnologias na organização do mundo atual e na capacidade do professor em lidar com as diversas tecnologias, interpretando sua linguagem e criando novas formas de expressão, além de distinguir como, quando e por que são importantes e devem ser utilizadas no processo educativo. (LEITE; SAMPAIO, 2002, p. 75).

Essa conceituação apresentada pelas autoras vem ao encontro de nossas necessidades como professor, pois às vezes não sabemos como, quando e por que utilizamos esses meios tecnológicos Necessitamos mais que nunca de uma formação contínua, de sermos alfabetizados na tecnologia, pois a velocidade com que essas vêm surgindo não tem como estarmos antenados apenas nas meras tecnologias que já conhecemos e dominamos no nosso cotidiano escolar (giz, quadro, TV/DVD, etc.). Com isso esperamos poder contribuir para uma educação que faça o nosso aluno desempenhar o seu papel de um ser crítico, político e participativo na construção de uma sociedade para todos.

\section{1 - A aprendizagem colaborativa e interação - construto de um aprendizado significativo}

Diversas são discussões trazidas pelos pesquisadores que abordam os estudos referentes às Novas Tecnologias e educação, em especial no processo ensino-aprendizagem do educando. No caso de Masetto (2000), expõe como fundamental a auto-aprendizagem em que o aluno constrói o conhecimento junto com o outro, podendo este ser o professor ou outro aluno (aprendizagem colaborativa), e a interaprendizagem onde ele por si só elabora o seu próprio conhecimento, tendo ele autonomia em seu processo de ensino-aprendizagem.

As definições relativas à aprendizagem colaborativa são vastas, mas a que vamos referir em nossos estudos, é buscada em Figueiredo (2006). Valendo ressaltar que alguns estudiosos buscam a aprendizagem cooperativa que não vem ao nosso caso neste momento, pois segundo Figueiredo (2006) essa aprendizagem é centrada no produto e não processo, porém ainda define que ambas favorecem a interação e autonomia do aprendiz.

A par de tantas observações feitas, merece ser destacado que: 
a aprendizagem colaborativa é uma abordagem construtivista, que se refere, grosso modo, a situações educacionais em que duas ou mais pessoas aprendem ou tentam aprender algo juntas, seja por meio de interações em sala de aula ou fora dela, seja por intermédio de interações mediadas pelo computador (Dillenbourg, 1999), cuja ênfase recai na co-construção do conhecimento dentro e a partir dessas interações. (FIGUEIREDO, 2006, p. 12; grifo do autor).

Esse processo de colaboração vem ao encontro das nossas práticas em elencar uma troca de conhecimentos entre nossos educandos e com isso fazer com que os mesmos sejam capazes de fazer descobertas entre si e também repassar as mesmas aos outros.

A interação em sala de aula é uma das propostas de maior observação acerca do aprendizado. De acordo com Figueiredo (2006), na construção do conhecimento de uma segunda língua deve-se proporcionar aos alunos situações de interação frequente e extensa na língua alvo, oportunidades favorecidas por um modelo de ensino que promova a aprendizagem colaborativa. É a partir daí que buscamos observar que o desenvolvimento do aluno é maior de que o seu aprendizado, pois

a influência do aprendizado nunca é específica. A partir de seus estudos dos princípios estruturais, afirmam que o processo de aprendizado não pode, nunca, ser reduzido simplesmente à formação de habilidades, mas incorpora uma ordem, intelectual que torna possível a transferência de princípios gerais descobertos durante a solução de uma tarefa para varias outras tarefas. Desse ponto de vista, a criança durante o aprendizado de uma determinada operação, adquire a capacidade de criar estruturas de um certo tipo, independentemente dos materiais com os quais ela está trabalhando e dos elementos particulares envolvidos. (VYGOTSKY, 1998, p. 108-109).

É notório que, quando desenvolvemos com nossos alunos atividades colaborativas estamos promovendo o aprendizado e também o seu desenvolvimento, algo que irá proporcioná-lo abrir novos caminhos a outros aprendizados. E de acordo com Figueiredo (2006), o que importa na aprendizagem colaborativa não é o sucesso do grupo em realizar a atividade proposta, mas sim a construção do conhecimento que é constituído de trocas significativas com o outro com quem se desenvolve a atividade, e isso sim é o verdadeiro desenvolvimento sócio-cognitivo do aluno.

Em nossos estudos duas situações importantes são observadas em Figueiredo (2006), uma delas é a importância que o professor tem perante a aprendizagem colaborativa, a de papel de mediador, colaborador de um apoio cognitivo afetivo para o aluno. A outra é a aprendizagem colaborativa no meio virtual, pois segundo o autor a interação mediada pelo 
computador é uma forma a mais de socialização. Além do que já observamos em Kenski (2003), Marcuschi (2005), caminhos para a produção linguística (os gêneros e a linguagem) e o aprendizado assim defendido por Masetto (2000), podendo desencadear a interaprendizagem e auto-aprendizagem do educando, e assim complementa que

algumas vantagens do meio eletrônico são, por exemplo, o rompimento de limitações espaciais e temporais, propiciando o acesso a um grande número de participantes para interagir, o que faz com que a aprendizagem seja favorecida pelas trocas interacionais e pela colaboração entre os participantes. (FIGUEIREDO, 2006, p.28).

Todo esse processo de aprendizagem colaborativa nos remete que o aprendizado pode acontecer de forma prazerosa e nem sempre necessita ser na sala de aula. Podemos encaminhar nossos alunos a espaços capazes de conduzi-los ao encontro do aprendizado e do desenvolvimento por meio da interação, proporcionando-lhes a alcançar a autonomia do saber.

\section{2 - Blog - uma ferramenta de medicação pedagógica}

Criar um espaço no qual os nossos alunos pudessem aprender de forma prazerosa, registrar os acontecimentos desse aprendizado e também observar o que outro estava produzindo, recorremos ao uso do blog como uma mediação pedagógica. Nesse contexto Oliveira; Cardoso (2009) ressaltam o uso do computador e Internet como meios pedagógicos que levam ao aprendizado de uma Língua Estrangeira, e no decorrer do uso dessas tecnologias na sala de aula dá ao aluno um aprendizado significativo sem constrangimentos. Os subsídios de nosso trabalho foram pautados em algumas literaturas que trazem o uso do blog como uma ferramenta de aprendizagem, bem como a sua definição.

O blog é um espaço de interação que possibilita a construção coletiva do conhecimento, visto que o aluno/professor poderá postar textos que serão lidos e comentados pelos demais participantes do curso. Nada mais é do que uma pagina da web onde os posts (textos) são apresentados em ordem cronológica inversa. (SILVA; CAVALCANTE, 2009, p. 7-8, grifo do autor).

A partir desta definição de blog é que os objetivos de nossa pesquisa foram embasados, pois necessitávamos utilizar uma interação que levaria à construção coletiva de 
um conhecimento por um grupo de educandos sob a observação do professor (eu). E ainda mais

os blogues podem ser ferramentas educativas eficazes uma vez que promovem a literacia ${ }^{4}$ verbal e visual, possibilitam a aprendizagem colaborativa e estão acessíveis de igual modo a vários grupos etários e fases de desenvolvimento educativo (Huffaker, 2005). É neste contexto que os blogues aparecem como ferramentas de eleição no ensino das línguas estrangeiras permitindo a participação activa dos alunos, a interacção e colaboração entre os pares e a comunicação inter-cultural autêntica com nativos, neste caso da língua inglesa, geográfica, e até culturalmente, distantes. (OLIVEIRA; CARDOSO, 2009, p. 88).

Nessa visão dos autores em relação ao uso do blog no ensino de LE (Língua Estrangeira), podemos mencionar que oferecem modos alternativos de ensino e possibilitam uma nova e excitante abordagem da aprendizagem comunicativa de línguas, oferecendo ao aluno uma nova razão para gostar da leitura e da escrita. E nessa interação do uso do blog e o ensino de língua estrangeira que observamos em Ortiz (2008, p. 67) “uma segunda língua é aprendida unicamente quando o falante estima que pode obter vantagens em utilizar outro idioma cujo raio de atuação é mais amplo”. E também corroborar com o que já mencionamos anteriormente embasados em Figueiredo (2006), sobre a aprendizagem colaborativa a qual leva o educando a interação sócio-cognitiva e um aprendizado significativo.

Entender essa ferramenta talvez não seja tão difícil já que muitos pesquisadores nos trazem conhecimentos básicos acerca dela, bem como formas de uso para poder levá-la ao construto do processo ensino-aprendizagem.

Sabemos que a expressão blog surgiu no final de 1997, foi cunhada por Jorn Barger para descrever sites pessoais, cujas alterações aconteciam a cada dia, um diário eletrônico. $\mathrm{Na}$ verdade o termo em si surgiu a partir de duas palavras Web e log (Weblog), e com isso cabe salientar que:

os blogs têm uma história própria, uma função específica e uma estrutura que os caracteriza como um gênero, embora extremamente variados nas peças textuais que albergam. Hoje são praticados em grande escala e estão fadados a se tornarem cada vez mais populares pelo enorme apelo pessoal. (MARCUSCHI, 2005, p. 60; grifo do autor).

\footnotetext{
${ }^{4}$ Literacia - ser capaz de perceber bem idéias novas para usá-las quando necessárias. Saber como aprender.
} 
Convém destacarmos que o uso maciço dos blogs vem fazendo com que se substituam os sites para nos auxiliar como uma ferramenta pedagógica e até mesmo como um meio de divulgação e postagem das atividades propostas em sala de aula e, acabam assumindo o papel de uma agenda eletrônica.

Procuramos no decorrer do desenvolvimento de nosso trabalho fazer uso da tecnologia em nossa sala de aula de forma absolutamente clara para os alunos, de modo que estivessem conscientes de todos os objetivos propostos. Não usamos o blog apenas como um recurso pedagógico, mas numa estratégia pedagógica de ensino que conduzisse os alunos a aprenderem e desenvolverem competências através das atividades de pesquisa que envolviam interpretação, seleção, síntese e postagem.

\section{3 - O método e o contexto da pesquisa}

A metodologia a qual se submeteu a nossa pesquisa foi a pesquisa-ação em uma abordagem qualitativa pautada em algumas literaturas já produzidas.

De acordo com estudos realizados em Bell (2008), a pesquisa-ação trata de uma pesquisa aplicada, realizada por profissionais que por conta própria identificaram um problema, necessidade de mudança ou melhora. E, segundo Denscombe (2007) in apud Bell (2008, p. 16), ela tem como objetivo "chegar a recomendações para uma boa prática, que lide com um problema ou melhore o desempenho da organização e dos indivíduos por meio de mudanças nas regras e procedimentos em que operam”. É nessa observação que elencamos a nossa pesquisa, buscamos fazer algo utilizando as Novas Tecnologias alicerçadas na aprendizagem colaborativa.

A pesquisa aconteceu numa turma de $1^{\circ}$ ano do Ensino Médio, em um Colégio na cidade de Pires do Rio - GO, junto à disciplina de Língua Espanhola, com a utilização do ambiente virtual para a execução da mesma. Sendo assim designado o URL: http://www.blogspot.com para a construção dos blogs, os quais seriam o meio de observação e avaliação do aluno no período da pesquisa que ocorreu no mês de maio do corrente ano de 2010.

As postagens no blog foram relativas ao conteúdo programático do $2^{\circ}$ bimestre do ano letivo de 2010, as quais abordavam um estudo acerca de 14 paises hispanohablantes: Argentina, Bolívia, Chile, Colômbia, Costa Rica, Cuba, Equador, Honduras, México, Paraguai, Peru, El Salvador, Uruguai e Venezuela. Os alunos deveriam postar a cada semana 
conteúdos referentes ao seu país (que foi designado por sorteio). Nas duas primeiras semanas o professor fez as orientações referentes às postagens e nas duas ultimas semanas as postagens ficaram a critério dos alunos.

As orientações feitas pelo professor em relação à pesquisa sobre os países foram: definição de cultura; mapa; a história; a bandeira, as línguas faladas e a oficial e por último, a cultura do país (isso foi postado nas duas primeiras semanas). Quanto ao trabalho livre feito pelos alunos foi bastante variados os temas, desde moda, futebol, hino nacional, curiosidades da culinária e origem do país (formação populacional). Todas as postagens no blog foram na língua espanhola.

Os sujeitos ${ }^{5}$ participantes da pesquisa foram 28 alunos de uma sala de $1^{\circ}$ ano do Ensino Médio, numa faixa etária entre 14 e 16 anos de idade, os quais trabalharam em duplas, perfazendo assim um total de 14 duplas, para melhor acontecer a divisão de conteúdos.

O questionário elaborado para levantamento do corpus da pesquisa, se continha de nove questões, das quais duas são fechadas e outras sete abertas. Todas relacionadas com o nível de conhecimento e utilização da Informática (meios tecnológicos), com o desenvolvimento do trabalho, o uso do blog, a relação do trabalho em pares (colaborativo), os quais entenderemos com mais profundidade na análise dos dados.

\section{4 - Análise dos dados: a concretização da nossa pesquisa}

O mundo globalizado em que está inserido o nosso educando exige dele interação com os novos meios tecnológicos desde sua tenra idade, o que aqui buscaremos explicitar em nossa pesquisa de acordo com o questionário, ao qual foram submetidos os 28 alunos integrantes do corpus pesquisado.

Já que o nosso estudo se dá junto ao uso do computador, buscamos saber de nossos alunos qual o nível de conhecimento que eles têm em Informática. Os resultados foram satisfatórios, sendo 34,9\% dizem ter o conhecimento básico, 61,2\% conhecimento intermediário e 3,9\% conhecimento avançado. Isso corroborou o nosso trabalho, mas era necessário saber mais, pois as atividades necessitariam do uso da Internet fora do espaço escolar, para tanto precisávamos saber qual a frequência do uso desse recurso, e assim constatamos pelas respostas que: $64,5 \%$ acessam a internet todos os dias, $11,5 \%$ duas vezes

\footnotetext{
${ }^{5}$ Aqui em nossa pesquisa usaremos pseudônimos dos participantes para resguardar as suas identidades.
} 
ou mais por semana, $11,5 \%$ somente aos finais de semana e outros $11,5 \%$ duas vezes ou mais por mês. Junto a essa mesma questão, buscamos nos informar sobre o local de acesso da Internet, sendo apontados: 73,2\% acessam de suas próprias casas, 15,3\% de lan house, 11,6\% de outro local (escritório do pai, laboratório da escola, biblioteca pública e casa de amigos). Buscamos aqui quantificar os nossos dados para melhor entendimento, para que aos poucos façamos uma análise descritiva das outras seis questões que ainda nos faltam.

O uso do blog foi algo fundamental nesta pesquisa, por isso na questão 3 questionamos o seguinte: Você já havia utilizado Blog antes? Em caso positivo de que forma? Os alunos foram contundentes em suas respostas aqui quantificadas o seguinte: $77 \%$ responderam que nunca haviam utilizado o blog antes e $23 \%$ responderam que sim. Duas dessas respostas nos chamaram mais atenção:

Sophie - Sim, eu já havia usado um blog, mas para ter contato com outras pessoas mas nunca como trabalho de escola.

Psytron Jackson - Sim já usei. Não foi positivo, usei para derrubar servidores de jogos, apagar HDS, cancelamento de internet, invasão de site de lojas, etc.

A aluna Sophie fez uso adequado do blog, pois o mesmo foi criado para este fim. Porém quanto a Psytron Jackson essa observação já é de forma negativa, pois como ele afirma, a Internet tem o poder de levar um jovem a cometer pequenos delitos como esses. $\mathrm{Ou}$ seja, não utiliza essa ferramenta como forma de construção de conhecimentos sem lesar outras pessoas.

O processo de interação é muito importante, Vygotsky (1998) menciona que a interação leva o educando ao desenvolvimento, e esse o leva a construir vários conhecimentos. Partindo disso, fizemos a quanta pergunta:

Pesquisador - Como foi para você ter trabalhado com seu colega na construção e execução do Blog?

Strep - Somente conhecer um pouco sobre o país que trabalhamos pois já estou acostumado a mexer com internet.

Edward Collin - Foi muito bom! Além de ter novas formas de se aprender, podemos nos interagir mais uns com os outros.

Cristina - Foi muito bom pois nós duas pensamos no mesmo assunto e conseguimos pesquisar mais sobre o assunto. 
Anderson Nogueira - Foi uma boa experiência, podendo assim explorar mais o mundo tecnológico, averiguando e observando melhor culturas distintas e diferentes da nossa.

Renata - Foi bom, porque foi uma experiência nova pois nunca tinha utilizado o blog antes.

Lara - Foi uma ótima experiência, além de podermos interagir mais com nossos colegas, podemos usufruir da tecnologia para melhor conhecimento.

As respostas aqui observadas foram contundentes e de uma forma geral, representa o que a maioria apontou: interação maior com o colega, de aprendizado e organização do trabalho executado. Cada um nos fez perceber como foi importante essa interação e, com isso, pudéssemos observar de forma mais precisa a aprendizagem colaborativa.

Tudo que fazemos nos proporciona alguma coisa, tanto com aspecto positivo ou negativo, assim questionamos na quinta questão:

Pesquisador - O que o uso do Blog te proporcionou? Dê detalhes.

Psytron Jackson - Raiva, muita Raiva por “apanhar” muito quando comecei.

Psynick - a interação com o colega, aprendizado.

Gaina - Essa nova forma de realizar um trabalho, além de me fazer adquirir um conhecimento das culturas principais de outro país me fez conhecer um novo caminho para adquirir e transmitir saberes.

Antonela - Achei uma forma mais prática de aprender sobre outras culturas, de estar utilizando a internet para novos meios de aprendizagem.

Anderson Nogueira - O blog pode proporcionar mais informação, por meio de fotos, textos, curiosidades, podendo ampliar meu conhecimento e estendendo o vocabulário em termos de outras línguas.

Essa nova experiência por alguns relatada como uma nova forma de aprender e de conhecer melhor a cultura dos países hispanohablantes estudados e a Língua Espanhola, refletem o quanto a tecnologia pode ser benéfica à educação.

Sabemos que o espaço da sala de aula às vezes inibe o aluno quando tem que se posicionar frente à turma ao ser questionado. Pallof; Pratt (2002) mencionam que é no ciberespaço (sala virtual) que essa timidez e medo de represália desaparece por completo, e com isso o aluno se torna um aprendiz ativo. Buscamos saber na opinião de nossos alunos na sexta questão um pouco sobre o comportamento deles nessa situação. 
Pesquisador - Em relação ao conteúdo de Língua Espanhola abordado em sua pesquisa, fizemos um trabalho intercultural com o uso dessa mediação pedagógica (Internet). Comente sobre essa forma de trabalho comparando-o com uma apresentação oral.

Gabriella - Gostei muito dessa nova forma de fazer um trabalho, é mais interessante e divertido foi melhor do que trabalhos em sala que são muito cansativos.

Antonela - Olha os dois meios seriam bem aproveitados pois, tanto para usar o Blog, tanto para apresentar oralmente, estudaríamos sobre o assunto. Mas gostei de ter sido com o Blog, pois poderia usar métodos diferentes para apresentá-lo, como: ferramentas que só na Internet tem.

Cristina - É bem mais prático do que a apresentação oral, porque as vezes muitas pessoas sentem vergonha e não consegue falar na frente de muitas pessoas e o blog nos ajudou no aprendizado mas sem ter medo da apresentação.

José - O trabalho no blog foi bom mais se tivesse uma apresentação oral o aprendizado seria melhor.

Caio - Um trabalho muito bom dando liberdade para fazer tranquilamente.

Rosa - A atividade realizada na internet é mais legal, pois estamos em casa ou em outro lugar, mas fora da escola sem aquela pressão de sala de aula, não há um nervosismo como na apresentação oral.

O medo que assola os alunos é um empecilho, quando se tem que enfrentar os colegas principalmente frente a atividade comunicativa no ensino de Língua Estrangeira. Os mesmos acharam o trabalho de forma mais prática e viável parcialmente por não ter uma apresentação oral, mas o caminho utilizado para a execução do trabalho segundo eles foi de grande aproveitamento. Aqui chamou a nossa atenção a resposta de José, pois a mesma vai ao contrário das outras demais que, asseguraram a praticidade do trabalho, que o aprendizado significativo e uma interação entre os pares.

O processo ensino-aprendizagem é algo que muito nos preocupa em relação aos nossos educandos, buscamos sempre em nossos planejamentos assegurar atividades que proporcionem um aprendizado seguro e eficaz. Na sétima questão buscamos saber deles sobre isso com a seguinte pergunta:.

Pesquisador - Comente sobre seu próprio aprendizado em relação ao que foi proposto pelo professor perante essa atividade. 
Anderson Nogueira - A aprendizagem com a atividade proposta foi positiva, pude conhecer melhor outra cultura e "invadir" o meio tecnológico ampliando também a forma de comunicação.

Antonela - Penso que meu aproveitamento foi positivo pois além de ter havido uma interação entre os blogs (pelo menos de minha parte), achei mais fácil e interessante para guardar as informações propostas.

Pinhão - Eu aprendi que a tecnologia pode até ser usada na escola, facilitando o aprendizado, mas com toda esta tecnologia os professores não confiam nos alunos e preferem os trabalhos feitos rudimentarmente (a mão).

Esse aprendizado que é demonstrado através das palavras de nossos educandos corrobora com as nossas expectativas e anseios em relação a um aprendizado significado junto ao uso das novas tecnologias como mediação pedagógica do processo ensinoaprendizagem. A par dessas considerações podemos entender melhor as respostas dadas ao oitavo questionamento.

Pesquisador - Quais são suas considerações referentes ao uso das Novas tecnologias no processo ensino-aprendizagem?

Pinhão - Poderia ser até uma boa chance de inclusão digital facilitando o processo de aprendizagem.

Psynick - As novas tecnologias nos proporciona, posso dizer com mais detalhes as pesquisas, a forma de apresentar trabalho, um exemplo o data show, que pode ser a apresentação de slides para melhor explicação.

Lara - Com um mundo globalizado é preciso levar a tecnologia também para a educação, essa é uma boa forma de podermos aprender e conhecer mais.

Samira - É muito proveitoso. Abre caminhos para aprofundação dos conteúdos.

Nikolle - As tecnologias utilizadas para o ensino e aprendizagem favorável um melhor entendimento por parte do aluno sobre a matéria, sendo bastante interessante utilizá-las.

Edward Collin - Eu considero as Novas Tecnologias como um meio mais simples e fácil de se aprender. Porém essas tecnologias devem ser utilizadas de forma correta e com bastante seriedade.

Rosa - Achei mais produtiva, porque os jovens de hoje vive no mundo da internet, então é uma forma de se interagir mais com o aluno, é mais prático e também inovador, pois nenhum outro professor fez essa atividade. 
Percebemos as Novas Tecnologias é motivo de orgulho para o processo educacional em si, pois até mesmo os alunos observam a sua importância e a vitalidade que a mesma dá às aulas, aspectos presentes em alguns relatos. Isso faz com que os alunos tenham um interesse maior pelas aulas e que o seu aprendizado é mais significativo, ou seja, a interação também foi fundamental para isso, segundo nossos alunos.

As últimas considerações feitas em nossa pesquisa sobre o questionário são em relação à seguinte pergunta: O que você diria a outros professores/colegas sobre essa experiência? Muito contribuiu para nossa avaliação, pois observamos algumas considerações que dizem da forma significativa que executou o trabalho, que outros professores devem utilizar os meios tecnológicos para execução de trabalhos, que deve sim sempre haver essa interação entre educação e tecnologia. Sem contar algo muito elucidativo que Rosa mencionou: “da à liberdade ao aluno e também ao professor”. Essa liberdade que leva esse aluno a construir o seu próprio conhecimento, um conhecimento autônomo, que foi gerado através dos processos de interaprendizagem e da auto-aprendizagem.

\section{5 - Considerações finais}

A nossa pesquisa buscou no decorrer das atividades propostas junto aos nossos alunos fazer uma triagem com o nosso arcabouço teórico metodológico e chegar a considerações relevantes acerca de que com o uso das Novas Tecnologias (blog) o nosso aluno conhecesse um pouco mais dos países hispanohablantes, sob a abordagem da aprendizagem colaborativa.

Isso foi levado a cabo em nossa pesquisa mas algumas limitações sempre aparecem, pois alguns alunos às vezes não cumpriram os prazos previstos, já que a cada semana tinha que postar algo novo, e assim umas três duplas acabaram postando tudo ao final do trabalho. Uma outra dificuldade que eles encontraram foi em fazer as postagem na língua alvo (Língua Espanhola), e em alguns momentos devido o contingente de atividades da escola, tinham que utilizar o tradutor em algumas partes.

Eu enquanto professor também tive minhas limitações, pois nunca havia usado o blog para fazer um trabalho desta natureza, por isso o medo de chegar ao final da atividade e perceber que o que foi proposto por mim no planejamento deu errado, afligia. Mas valeu a pena, pois segundo os relatos dos alunos aconteceu sim a aprendizagem, a interação e sem contar que os mesmos viram o quanto as Novas Tecnologias contribuem para o processo ensino-aprendizagem. 
Esse processo de pesquisa-ação ao qual submeti, faz com que esteja sempre centrado em nossa prática diária o uso de novas metodologias, a busca pelo novo que leve nosso educando a uma aprendizagem significativa. Por isso aqui buscamos

possibilitar a avaliação pelos pares e quebrar as barreiras das quatro paredes da sala de aula, o blogue quebrou barreiras em termos colaborativos, tendo ajudado a atingir os objetivos da sala de aula do terceiro milênio: colaboração, inclusão, flexibilidade e aumento da importância dada aos alunos. (OLIVEIRA; CARDOSO, 2009, p. 94)

O uso do blog nos proporcionou chegar a considerações de que através do novo, do diferente, é possível sim acontecer o aprendizado e ainda mais, através da interação ocorrer o desenvolvimento do educando, a fim de abrir caminhos para outros aprendizados. A abordagem a qual submetemos a execução de nossas atividades que foi aprendizagem colaborativa e que de acordo com Figueiredo (2006, p. 23) "na sala de aula em que se adota uma perspectiva colaborativa os alunos tornam-se participantes ativos no processo aprendizagem. Eles têm a oportunidade de aprender com os colegas e de ensinar-lhes.”, isso é que fez de nosso trabalho, algo relevante e significativo, pois levamos o nosso educando através do uso das Novas Tecnologias por meio da aprendizagem colaborativa à autonomia do aprendizado.

\section{6 - Referências}

BELL, J. Abordagens de pesquisa. In: Projeto de pesquisa: guia para pesquisadores iniciantes em educação, saúde e ciências sociais. 4. ed. Porto Alegre: Artmed/Bookman, 2008, p. 13-30.

CANCLINI, N. G. A globalização imaginada. São Paulo: Ed. Iluminuras, 2003.

FIGUEIREDO, F. J. Q. A aprendizagem colaborativa de línguas: algumas considerações conceituais e terminológicas. In: (org). A aprendizagem colaborativa. Goiânia: Ed. da UFG, 2006, p. 11-45.

KENSKI, V. M. Tecnologias e ensino presencial e a distância. 3. ed. Campinas: Papirus. 2006. 
LEITE, L. S.; SAMPAIO, M. N. Alfabetização tecnológica do professor. In: Alfabetização tecnológica do professor. 3. ed. Petrópolis: Vozes, 2002, p.51-76.

MARCUSCHI, L.A. Gêneros textuais emergentes no contexto da tecnologia digital. In: ; XAVIER, A.C. (orgs.). Hipertexto e gêneros digitais: novas formas de construção do sentido. 2. ed. Rio de Janeiro: Lucerna, 2005, p. 13-67.

MASETTO, M. T. Mediação pedagógica e o uso da tecnologia. In: MORAN, J. M.; MASETTO, M. T.; BEHRENS, M. A. (orgs). Novas Tecnologias e mediação pedagógica. Campinas, SP: Papirus, 2000, p. 133-173.

OLIVEIRA, A. S.; CARDOSO, E. L. Novas perspectivas no ensino da língua inglesa: blogues e podcasts. Educação, Formação \& Tecnologias, v. 2 (1); p. 87-101, 2009. Disponível em: <http://eft.educom.pt/index.php/eft/index>. Acesso em: 09 jun. 2010.

PALLOF, R. M.; PRATT, K. Construindo Comunidades de Aprendizagem no Ciberespaço. Porto Alegre: Artmed, 2002.

SILVA, K. C.; CAVALCANTE, P. S. Mediação pedagógica em curso superior de computação e informática a distância: as estratégias de ensino utilizadas por docentes online. (2009). In: <http://webradioabed.blogspot.com/2009/08/mais-uma-lista-de-trabalhosaprovados.html>. Acesso em: 30 maio 2010.

VYGOTSKY, L. S. Interação entre aprendizado e desenvolvimento. In: . A formação social da mente. São Paulo: Martins Fontes, 1998, p. 103-119. 